\title{
Behaviour as input for modelling dispersal of fish larvae: behaviour, biogeography, hydrodynamics, ontogeny, physiology and phylogeny meet hydrography
}

\author{
Jeffrey M. Leis* \\ Ichthyology, Australian Museum, 6 College Street, Sydney, New South Wales 2010, Australia
}

\begin{abstract}
Both morphology and behaviour develop during the pelagic larval stage of demersal teleost fishes. Demersal perciform fishes from warm-water habitats begin their pelagic larval stage as plankton but end it as nekton, with behavioural capabilities (including swimming, orientation and sensory abilities) that can influence, if not control, dispersal trajectories. The ontogeny of these behaviours, and the gradual transition from plankton to nekton, are central to understanding how larval fishes can influence dispersal and how behaviour can be integrated into dispersal models. Recent behavioural research shows that, from about 5 to $8 \mathrm{~mm}$ standard length, larvae of warm-water perciform fishes can directly influence dispersal, because they swim in an efficient inertial hydrodynamic environment, can swim for kilometres at speeds that heuristic models show will alter dispersal trajectories, can swim faster than ambient currents before settlement, can orientate in the pelagic environment and can detect sensory cues (light, sound, odour) that allow orientation. Fish larvae also control their vertical position (which may change temporally, spatially and ontogenetically), allowing indirect influence on dispersal. Most research on larval behaviour relevant to dispersal (i.e. swimming, orientation and sensory abilities) has been done with warm-water perciform species. This invites the question: Will the same be found in cool water or in species of other orders? The hydrodynamic and physiological effects of temperature indicate that larvae in warm water should swim more efficiently and initially at smaller sizes than larvae in cool water. Limited evidence suggests that larvae of perciform fishes are more behaviourally competent and attain morphological and behavioural milestones when smaller (and probably younger) than do larvae of clupeiform, gadiform and pleuronectiform (CGP) fishes. Perciform fishes dominate demersal fish communities in warm water, whereas CGP fishes dominate in cooler waters. These hydrodynamic, physiological, ontogenetic, phylogenetic and biogeographic factors imply that larval fish behaviour may have more influence on dispersal in warm seas than in cool seas. This hypothesis requires testing. Additional factors that should be taken into account when using behaviour of larvae to produce biophysical models of dispersal are discussed.
\end{abstract}

KEY WORDS: Fish larvae · Dispersal · Connectivity · Behaviour · Biophysical model $\cdot$ Swimming · Orientation $\cdot$ Sensory cues $\cdot$ Marine protected areas

Resale or republication not permitted without written consent of the publisher

\section{INTRODUCTION}

The fact that the large majority of marine, demersal, teleost fishes have a pelagic larval stage (Moser et al. 1984, Leis 1991, Fuiman \& Werner 2002) has important implications for the dynamics of fish populations and for human management of them. Marine fish popula- tions are thought to be open, with young potentially derived from sources perhaps many kilometres away (Sale 1991, 2004, Caley et al. 1996). Connectivity is the process that links these populations by dispersal (Palumbi 2003), and, for demersal teleost fishes, this takes place primarily during the pelagic larval stage, as it does for most marine invertebrates (Leis 1991, 
Morgan 2001). Therefore, for most species, it is the pelagic larval stage, rather than the demersal adult stage, that sets the spatial scale for population connectivity and for the geographic size of fish populations (Cowen 2002, Sale 2004). Further, most mortality in marine fishes takes place during the pelagic stage (e.g. Cushing 1990), which limits the distances over which meaningful dispersal takes place (Cowen et al. 2000, 2006).

Understanding the scale of connectivity by dispersal during the pelagic larval stage is a major challenge in marine ecology (Cowen 2002, Sale 2004), and it is clear that management of marine fishes must incorporate the scales over which their populations are connected (Palumbi 2001, Cowen et al. 2003). For example, marine protected areas (MPAs) are expected to fulfil both biodiversity conservation and fishery replenishment roles, and their effectiveness in both depends on the scale of connectivity (Palumbi 2003). A major question of scale is whether MPAs can replenish themselves; however, regardless of their ability to do this, MPAs will not fulfil the fishery role for all exploited areas in between them if spaced too far apart. The MPA biodiversity role requires maintenance of genetic connections between MPAs, and, although this demands a lower and less regular exchange of propagules than does fishery replenishment, for optimal MPA design, it is important to understand the spatial scales involved.

Dispersal in marine systems has usually been assumed to operate over very large distances (100s of kilometres), with management scaled accordingly. We now know that marine fish populations can be demographically structured at more modest spatial scales; in some cases as little as 10 s to 100 s of metres (Iles \& Sinclair 1982, Sinclair 1988, Swearer et al. 2002, Jones et al. 2005, Cowen et al. 2006). Predictive, individually based dispersal models provide a productive way to address the challenge of quantifying both the spatial and temporal scales of connectivity and the factors that contribute to them.

The importance of understanding where larvae are going and where they are coming from has led to dozens of models of dispersal as a purely physical process. These attempts make the 'simplifying assumption' (e.g. Frank et al. 1993, Roberts 1997, Leis 2006) that pelagic larvae of demersal fishes have swimming and orientation abilities so limited as to be irrelevant to dispersal: they treat larvae as passive particles. From this perspective, the only biological variable relevant to dispersal outcomes is the pelagic larval duration (PLD). No one contests the relevance of hydrography to dispersal, but, in contrast, until recently, larval behaviour other than vertical distribution has effectively been ignored in most dispersal models. This is changing rapidly. For example, James et al. (2002) state that 'further work is needed with more computationally intensive 3D circulation models to investigate the possible effects of known or proposed larval behaviours'. This is exactly what is required, but, increasingly, this can be based on known, rather than proposed, behaviour.

My goal here is not to review the literature on behavioural capabilities of fish larvae-this has been done elsewhere (see references below). Rather, I will attempt to briefly summarise the kinds of documented behaviours of fish larvae that are relevant to dispersal (dispersal-relevant behaviour). Reviews will be cited to point the reader who is interested in more detail in the right direction. I will argue that we now know enough about the behavioural capabilities of fish larvae that we should expect them to influence dispersal outcomes, and must, therefore, include them in our dispersal models. Then, I will provide a 'shopping list' and brief discussion of factors that I argue should be taken into account when incorporating the behaviour of fish larvae into hydrodynamic models if the goal is to produce realistic biophysical models of dispersal.

The present paper focuses on the pelagic, dispersive stage of demersal, teleost fishes. For the purposes of this paper, an ecological rather than morphological definition is adopted-this stage begins when the propagule leaves the adult, demersal habitat (at spawning for pelagic eggs and at hatching for nonpelagic eggs) and ends at settlement from the pelagic habitat. This focuses attention on the pelagic, potentially dispersive stage, regardless of what it is called, and has the advantage of avoiding sterile nomenclatural debates over when a larva becomes a juvenile. Behaviour has long been recognised as an important input to dispersal of adult, pelagic fishes, and adults of these species are, in general, more mobile than are demersal fish species. Much of what is said here about larvae of demersal fishes might also apply to larvae of pelagic species, but there has been relatively little study of dispersal-relevant behaviour in larvae of pelagic fishes. It is nearly certain that some differences will exist between larvae of demersal and pelagic species, and until we have data on behavioural capabilities of larvae of the latter, it is unwise to assume the two are equivalent.

\section{DISCUSSION}

\section{Why behaviour of fish larvae can influence dispersal outcomes}

Integration of biological and physical inputs has been impeded by poor knowledge of the behaviour of 
fish larvae during their pelagic sojourn away from the demersal adult habitat and during the extraordinary ecological and morphological transition from the pelagic to benthic phase, which is termed settlement. Recent research on warm-water, larval marine, perciform fishes has revealed remarkable behavioural abilities that make the simplifying assumption untenable. We now know that, for most of the pelagic stage, these larvae are capable of exerting considerable direct and indirect behavioural control over their dispersal trajectories (reviewed by Kingsford et al. 2002, Leis \& McCormick 2002, Sponaugle et al. 2002, Leis 2006, Montgomery et al. 2006). Larvae of warm-water, perciform demersal fishes have impressive behavioural capabilities (less is known about species in other orders), and heuristic models indicate that speeds and behaviours that are able to strongly influence dispersal trajectories both directly and indirectly are well within their capabilities (see review by Leis 2006). These behaviours are not reviewed in detail here. Rather, a brief summary is provided about what is known of the behavioural capabilities of larvae of warm-water perciform fishes, and relevant review papers are cited. Other than vertical distribution, research on behaviour of larvae from cool-water and non-perciform species has focused on feeding and predator avoidance, and dispersal-relevant behaviour has received little attention. Because so little is known about dispersalrelevant behaviour in larvae of cool-water species and in larvae of non-perciform species, this paper focuses on demersal, perciform species of warm-water fishes. I will then build upon Hunt von Herbing's (2002) hypothesis that in warm marine waters, swimming abilities of fish larvae are more likely to be able to directly influence dispersal outcomes than in cool waters, and the reasons for thinking this might be so.

\section{Behavioural abilities of relevance to dispersal}

It should be understood that the following refers to larvae of warm-water, demersal, perciform fish species. In no case do we have complete knowledge of all dispersal-relevant behaviours for any one species, and, for some types of behaviour, only a few species have been studied.

Vertical distribution can indirectly influence dispersal of fish larvae, and it is clearly under control of the larvae (see reviews by Pearre 1979, Sponaugle et al. 2002, Leis 2006). It is well established that vertical distribution of fish larvae is under precise behavioural control from very early in the PLD, often changes ontogenetically (and over other time scales), and may vary spatially. It has long been recognised that behaviour affecting non-random, vertical distribution can strongly influence dispersal outcomes where current velocity is not uniform vertically; this has been demonstrated in both warm and cold waters and with larvae from a variety of orders.

Horizontal swimming by fish larvae can directly influence dispersal if it is of sufficient speed, can be maintained for sufficient periods of time, and is orientated. Swimming speeds of fish larvae can be considerable (see review by Leis 2006). Over most of the PLD, larvae can swim at speeds that remove the larvae from the inefficient viscous hydrodynamic environment, and heuristic models indicate that this behaviour can influence dispersal outcomes. Over much of the pelagic period larvae can swim at speeds that are similar to or greater than mean current speeds in many marine environments. These swimming speeds are 3 to 10 body lengths $\mathrm{s}^{-1}\left(\mathrm{BL} \mathrm{s}^{-1}\right)$ in the ocean, increase by 0.5 to $4.0 \mathrm{~cm} \mathrm{~s}^{-1}$ for each millimetre increase in size, and can exceed $50 \mathrm{~cm} \mathrm{~s}^{-1}$ at settlement.

Swimming speed must be combined with swimming endurance to influence dispersal outcomes, and fish larvae do have considerable swimming endurance (see review by Leis 2006). Over a major portion of the post-flexion stage, larvae can swim for kilometres to $10 \mathrm{~s}$ of kilometres, and this distance increases greatly with growth. Endurance may be nearly open-ended if larvae can feed, and larvae seem to be very energetically efficient when swimming (Nilsson et al. 2007).

Swimming in the absence of orientation is unlikely to influence dispersal outcomes, but fish larvae have good orientation abilities (see reviews by Kingsford et al. 2002, Leis 2006, Montgomery et al. 2006). The orientation abilities of individual larvae form early, reach a high precision by 5 to $8 \mathrm{~mm}$, and do not improve further with growth. On a population basis, orientation abilities form in larvae by 7 to $8 \mathrm{~mm}$. Direction of the orientation of larvae may change ontogenetically or between day and night. In short, larvae do not swim randomly on either an individual basis or a population basis, but the question of how this orientation is maintained remains.

Although other sensory cues may also be involved in orientation by fish larvae in the pelagic environment, there is clear evidence for the involvement of audition, olfaction and vision. Underwater sound can provide cues for orientation by larval fishes (see reviews by Montgomery et al. 2001, 2006, Kingsford et al. 2002, Myrberg \& Fuiman 2002). Fish larvae can hear when very small (8 to $9 \mathrm{~mm}$, which are the smallest larvae in which hearing abilities can currently be assessed; K. J. Wright pers. comm.) and perhaps throughout the pelagic phase. By settlement, and possibly earlier, larvae can distinguish among sounds and can locate underwater sound sources (i.e. use sound to navigate). 
The distances over which underwater sound can be utilised by fish larvae for orientation are unclear, but sound travels well with little attenuation in water, and its spread is independent of current, so it has the potential to provide orientation cues over many square kilometres.

Fish larvae can use olfactory cues for orientation (see reviews by Leis \& McCormick 2002, Kingsford et al. 2002, Atema et al. 2002, Wright et al. 2005). Very small larvae can detect dissolved materials $(9 \mathrm{~mm}$, which are the smallest larvae in which olfaction can currently be assessed; K. J. Wright pers. comm.). Using olfactory cues, settlement-stage larvae can distinguish among species, and among water types with different characteristics, and can locate odour sources. At present, this has been shown only over small spatial scales (10s of metres), usually in connection with settlement. Because the spread of odours is not independent of currents, odours may be less useful than sound for orientation.

Fish larvae can use vision for orientation (see reviews by Kingsford et al. 2002, Myrberg \& Fuiman 2002, Leis 2006). By the time of settlement, larvae can apparently see as well as human divers, although earlier in development, visual abilities are more limited. This visual ability is used in avoiding predators and selecting settlement sites, but this is limited by water clarity to $10 \mathrm{~s}$ of metres. There are indications, however, that settlement-stage larvae of some species may be able to use a solar compass, and, presumably, this is vision based.

There is little, if any, evidence that fish larvae can detect the speed and direction of currents in the pelagic environment, and thereby orientate their swimming into the current (see reviews by Leis 2006, Montgomery et al. 2006). A fish larva embedded in a moving water column may be able to detect turbulence (using its lateral line or otolith-based sensory system), and this might indicate it is within a current, but, without an external frame of reference, it cannot detect the direction or speed of the current. External reference points in the form of the ability to see the bottom, or, more speculatively, the ability to perceive, while drifting, the relative motion of a distant, fixed, sound source might be available and might enable a larva to determine the direction of the current, but this has not been demonstrated.

Species-specific patterns are an overriding theme in behavioural studies (see reviews by Leis \& McCormick 2002, Leis 2006). Because of this, we should expect different species to have differing behavioural influences on dispersal trajectories.

How a combination of such behaviours might influence dispersal can be demonstrated with larvae of the sparid Acanthopagrus australis off the Australian east coast. On average, larvae of this species swam toward the coast (NW) when 7 to $10 \mathrm{~mm}$ in length and then parallel to the coast (NE) when 10 to $13 \mathrm{~mm}$ in length (Leis et al. 2006). At the same size at which the change in swimming direction took place, this species moved upward into the neuston from a relatively uniform vertical distribution over the upper $10 \mathrm{~m}$ (Leis et al. 2006). Over this range of sizes, the in situ swimming speed of this species increased from 5 to $10 \mathrm{~cm} \mathrm{~s}^{-1}$, remaining at about $8 \mathrm{BL} \mathrm{s}^{-1}$ (Leis 2006), although the larvae can swim considerably faster (Clark et al. 2005). In contrast, over the same size range, there was no change in the precision of swimming directionality by individuals (Leis et al. 2006). This sparid settles into estuarine sea grasses, entering estuaries at 10 to $13 \mathrm{~mm}$, while swimming at or near the surface (Trnski 2002). This combination of behaviours would help keep the smaller larvae relatively near the coast until they were ready to settle, whereupon they would swim parallel to the coast at the surface. This would be an effective way to intersect estuarine plumes extending over the shelf that the larvae might be able to follow into the estuary (albeit, nothing is known of the sensory abilities of larval $A$. australis). Clearly, dispersal outcomes for larvae of $A$. australis would be different from the oft-assumed passive drift, and the portion of the PLD for which passive drift is a reasonable assumption will be small.

Given these capabilities, larvae of warm-water, perciform fishes have the behavioural potential to greatly influence dispersal trajectories. Now that these abilities are documented in a range of taxa, we can begin to incorporate them into dispersal models. Existing attempts to include behaviour of larvae into dispersal models have focused on vertical distribution, but have, more often than not, ignored ontogenetic changes or variance in vertical distribution behaviour (there are some honourable exceptions: e.g. Bartsch \& Knust 1994, Hare et al. 1999, Cowen et al. 2006). Attempts to include other behaviours (e.g. horizontal swimming, orientation abilities) have encountered difficulties because of a lack of appropriate data on relevant species, and modellers have sometimes resorted to the use of hypothesised abilities or arbitrary 'sensory zones' around settlement habitats (James et al. 2002, Cowen et al. 2006). Emerging data on the ontogeny of behaviour in the larvae of demersal fishes, and direct measurements of its variation will enable modellers to overcome this limitation and to fill the biological gap in contemporary dispersal models. This will allow the development of true biophysical dispersal models with realistic behavioural input and, therefore, realistic estimates of connectivity. 


\section{Could behaviour of larvae be more important in warm than in cool waters?}

The work summarised above on dispersal-relevant larval behaviour has concentrated on warm-water, perciform species. It is not clear that these results will apply to larvae from cold water or of other orders. In fact, we should expect differences in dispersal of larvae between cold- and warm-water environments (Hunt von Herbing 2002). In particular, in warmer waters, larval behaviour may have more influence on dispersal outcomes. The reasons for this expectation come from several sources.

First, both physics (water viscosity) and physiology (muscle efficiency) predict that swimming by fish larvae-particularly smaller ones - will be more efficient in warmer water. Water is more viscous when it is cold, and this makes swimming more difficult and energetically inefficient (Fuiman \& Batty 1997, Hunt von Herbing 2002, Leis 2006), and this effect is most pronounced for small larvae and larvae that swim slowly (e.g. 1 to $2 \mathrm{BL} \mathrm{s}^{-1}$ ). Further, larvae swimming in colder water operate over an inefficient range of muscle-fibre-shortening velocities, and this will have an impact on swimming efficiency and limit swimming performance (Hunt von Herbing 2002). In larval herring and plaice, muscle-contraction speed increases by about one-third when temperature increases from 5 to $12-15^{\circ} \mathrm{C}$ (Blaxter 1992), for example, and, in herring larvae, this leads to a doubling of the swimming speed (Batty et al. 1991).

Secondly, in warmer water, larvae may grow faster, thus reaching a given size sooner than in cooler water (Houde 1987, 1989), which means that ontogenetic milestones, both morphological and behavioural, will be reached sooner. All else being equal, this should mean that larvae will be able to behaviourally influence dispersal outcomes sooner in warm water.

Third, perciform fishes dominate demersal fish communities and catches in tropical waters, whereas, in cooler waters, other orders (e.g. Gadiformes) dominate. For example, in the warm waters of the eastern Pacific between Mexico and Peru, the 696 perciform species constitute $62 \%$ of the coastal teleost species (Robertson \& Allen 2002), whereas, in the much cooler waters of the Canadian Pacific, the 75 perciform species constitute only $30 \%$ of the coastal teleosts (Hart 1973). This is relevant to possible regional differences in dispersal, because perciform fishes seemingly reach developmental milestones at smaller sizes than do larvae of other orders (Moser et al. 1984, Moser 1996, Leis \& McCormick 2002, Leis \& Carson-Ewart 2004, Leis 2006), and the same presumably applies to behavioural milestones. Very limited information also suggests that larvae of perciform fishes may be more behaviourally capable at any given size than are larvae of other orders. In the clearest example of this, maximum routine swimming speeds (a measure of swimming speed in still water in the laboratory) of perciform larvae are of 2.5 to $11 \mathrm{BL} \mathrm{s}^{-1}$, whereas larvae of clupeiform, gadiform and pleuronectiform fishes can achieve only 1 to $1.5 \mathrm{BL} \mathrm{s}^{-1}$ (Leis 2006).

These physical, physiological, biogeographic, ontogenetic and phylogenetic factors lead to the expectation that, in tropical waters, fish larvae will have more behavioural influence over dispersal than occurs in cool temperate waters. Some aspects of the above reasoning remain to be properly verified (e.g. the assertion that perciform larvae have greater relative swimming speeds [i.e. BL s ${ }^{-1}$ ] than do larvae of other orders is based on limited data), and the overall hypothesis remains to be tested. Testing the hypothesis will require care to avoid confounded comparisons given the number of potentially interacting physical, physiological, biogeographic, ontogenetic and phylogenetic factors involved. Finally, if temperature is an important factor in determining the ability of fish larvae to behaviourally influence dispersal, then seasonal variation in this ability should be expected.

\section{Factors to consider when integrating behaviour of larvae of demersal fishes into numerical models of dispersal}

This listing should be considered a step toward 'best practice' in dispersal models, rather than an assertion that dispersal models have always failed to consider these things in the past. Most dispersal models have incorporated some or many of these factors, but numerous models, including contemporary ones, have not. (1) The numerical physical model must be 3-dimensional so vertical distribution behaviour can be taken into account. Although 3-dimensional dispersal models have been available for some time, 2-dimensional models are still being produced today.

(2) Behavioural capabilities of larval fishes are best incorporated into dispersal models if the models are individually based.

(3) Many behaviours may operate at dimensions that would be sub-scale given the grid size of most contemporary dispersal models, and it is possible that behavioural interactions with sub-scale hydrodynamic features, particularly in areas of topographic complexity, are important in determining dispersal outcomes. Therefore, at least in areas of topographic complexity, it may be necessary to use a finer scale model grid than has usually been the case in order to take behaviour into account. 
(4) When larvae are initially released into the ocean, their behavioural capabilities are poorly developed and may have little influence on their dispersal. So, it is particularly important to model the flow of water at a fine scale in the vicinity of the spawning location-which will frequently be an area of topographic complexity - to determine whether larvae can be passively retained near their natal area by fine-scale physical processes until they become behaviourally capable.

(5) Testing of both the physical portion of the models and of the integrated biophysical models is essential if they are to be credible. The former can utilise direct physical oceanographic measurements. The latter can use otolith data and physical markers (Thorrold et al. 2002) and some genetic measures (Hellberg et al. 2002).

(6) We need to be clear about whether a given model is to be used to examine demographic connectivity or genetic connectivity, as the spatial and temporal scales of the two are undoubtedly different (see 'Introduction'). For example, Cowen et al. (2006) recognised this and specified that they were concerned with demographic connectivity, which they defined as recruitment necessary to replace mortality.

(7) Understanding of adult fish behaviour with respect to the time and place of spawning needs to be improved to enable precise starting conditions to be incorporated into dispersal models. Some species spawn in a wide variety of locations, providing a diffuse source of propagules, whereas others spawn at particular, very limited, aggregation points, and thus provide a point source of propagules. In the same way, the timing of spawning can be either diffuse or concentrated. These starting conditions can have important implications for dispersal outcomes, yet, they are not always well understood, particularly in the tropics.

(8) Fish larvae (at least of perciform, warm-water demersal species) start their pelagic period as plankton but end it as nekton. This behavioural transition must be integrated into dispersal models. If the transition is considered at all, most models to date have arbitrarily divided the PLD into passive and active segments, ignoring the plankton to nekton transition. Tests with such models indicate that the duration of the passive segment has a very large effect on dispersal outcomes (e.g. James et al. 2002, Cowen et al. 2006). New behavioural data document more realistic gradual behavioural transitions, which can be incorporated into dispersal models.

(9) Larval fish behaviour varies both with ontogeny and among individuals. Not all individual larvae have equal abilities, and this among-individual behavioural variation-not just mean values - must be incorporated into dispersal models. Similarly, a $2 \mathrm{~mm}$ larva will behave differently than a $10 \mathrm{~mm}$ larva. Therefore, a key issue to be addressed is the best way to integrate this variation into hydrodynamic numerical models: the behavioural data must be size specific and the variation included in a form that can readily be incorporated into the model.

(10) A special kind of variation is best performance, and we need to investigate the dispersal implications of using data for the best performing individuals in dispersal models. Mortality rates of fish larvae are huge, and best performers (e.g. fastest growers; Jenkins \& King 2006) may preferentially survive. This concept may also apply to performance of dispersal-relevant behaviour, and, if so, average performance may not be the appropriate metric to include in dispersal models. Thus, model individuals can be assigned the best behavioural performance for swimming, orientation, sensory abilities, etc. Similarly, some individuals can also be assigned the fastest growth or shortest PLD. If behaviour is important to dispersal, a large difference in dispersal outcomes between average and best performers might be expected.

(11) Laboratory observations and experiments on behaviour must be ground-truthed with direct in situ observations and experiments. Dispersal takes place in the ocean, and it is extremely difficult to duplicate a pelagic environment in the laboratory. In situ swimming behaviour of larvae is different from that in the laboratory, for example (Leis 2006). Perhaps research using mesocosms can help bridge the gap between laboratory and field studies. If there are good relationships between laboratory and field measures of performance, predictions of field behaviour from laboratory behaviour or from larval morphology may be possible (Fisher et al. 2005, Leis 2006).

(12) In conjunction with the physical model, sensitivity analysis can be used to determine which real behaviours of larvae make a difference to dispersal outcomes. Swimming speed, orientation and vertical distribution will probably be influential in most cases. It is likely that some behaviours may have relatively little influence on dispersal outcomes (at least until a certain stage in development), so including in models all behaviours over the full PLD may not be practical or even desirable.

(13) Incorporation of mortality into dispersal models is necessary to make clear over what spatial scales connectivity of demographic significance can take place. The ability to relate growth and mortality 
rates to oceanographic conditions, both physical and biological, would be a valuable component of dispersal models, but may not be a realistic goal in the near future.

(14) A one-size-fits-all approach to incorporation of larval behaviour into models will be misleading at best, as it is clear that behaviour differs greatly among species. Extreme caution is necessary in applying data on behavioural information across taxonomic boundaries, particularly at the ordinal level. Therefore, modellers should seek to use behavioural data on the particular species of interest, or a close relative.

Biophysical, individually based models of dispersal are increasingly attempting to incorporate the behaviour of fish larvae and to apply the factors listed above. This was evident in many of the presentations at the WKAMF Workshop and in the papers included in this theme section resulting from it. In the broader literature, the most commonly included behaviour remains vertical distribution (e.g. Hare et al. 2002), with much less emphasis on horizontal swimming (e.g. Fox et al. 2006). Other contemporary models attempt to include swimming and sensory abilities of larvae indirectly in the form of 'active larval movement' and retention within a specified radius of settlement habitat once this radius is entered (e.g. Cowen et al. 2006). There is broad recognition of the importance of spawning location and time (e.g. Hinckley et al. 2001). Pushing other behavioural boundaries are attempts to incorporate mortality and growth as emergent properties of the model, and this involves behavioural interaction of larvae with prey and predators (e.g. Bartsch 2005). Clearly, many modellers are moving away from the concept of the passive larva, but this is not universal, and not enough of the behaviour input, other than vertical distribution, is empirically derived or based on the species being modelled.

\section{Research needs in larval behaviour}

Our empirical understanding of dispersal-relevant behaviour in fish larvae is still limited, particularly in the number of species studied. It is clear, however, that there are several areas where understanding is especially poor and where research is required to provide the empirical base from which to integrate behaviour into dispersal models. Aside from consideration of vertical distribution, observations of larval fish behaviour with conventional tools like plankton nets will seldom be informative. Lateral thinking is needed in this area.

We need a better understanding of the spatial scales over which sensory cues can be influential in orientation by fish larvae. We know, for example, that larval reef fishes can locate sources of sound or odours, but not from what distance. Nor do we know how they determine the direction to the sound or odour source.

Behaviour of larvae at night is particularly poorly understood, and this is an important gap to fill. Aside from vertical distribution studies using nets, we have very little field-based information on behaviour of larvae at night. Limited laboratory and field experiments indicate that behaviour can differ on a diel basis: swimming speed and direction can differ between day and night, for example (reviewed in Leis 2006). As night makes up an average of half the PLD, we need to know more about behaviour of larvae during that half. Similar arguments apply to behaviour at crepuscular periods and in poor weather conditions. There are indications that orientation of larvae can be less precise in cloudy conditions, for example (Leis \& Carson-Ewart 2003).

Behavioural performance is strongly size related, so we need to have a better understanding of growth trajectories of larvae in the wild to allow performance to be related clearly to age, as well as to size. We need to know when to turn on or off particular model behaviours, and, because behaviour is more related to size than to age, both size and age of larvae are important inputs for dispersal models.

Given the strong influence that mortality rates can have on the scale of connectivity (Cowen et al. 2000), obtaining better estimates of mortality rates in the sea is a priority. It will be important to investigate to what extent mortality rates are species specific. There are no field data on larval mortality for many species, and obtaining these will be a challenge. Many of the mortality estimates used in dispersal models (e.g. 0.1 to $0.5 \mathrm{~d}^{-1}$; James et al. 2002, Cowen et al. 2006) are from species that are, at best, not closely related to the species of interest, and many mortality estimates contain questionable assumptions.

Most available data on dispersal-relevant behaviour of larvae are from warm-temperate and -tropical species from a limited number of families. We need more data on cool- and cold-water taxa, and on a wider variety of families, because it seems that there are large among-species differences in behavioural capabilities and in the ontogeny of them.

\section{Conclusions}

I have summarised recent reviews that show the behavioural capabilities of larvae of warm-water, demersal, perciform fishes to be well developed from relatively early in the pelagic larval stage, and have argued that, because these capabilities have the potential to influence dispersal trajectories, they should be incorporated into biophysical dispersal models. Recent research makes it clear that larvae of at least 
warm-water perciform fishes have behavioural capabilities that can influence their dispersal trajectories. The present challenge is to determine if they use them for this purpose. In effect, this requires testing the simplifying assumption. Dispersal models can be used in this way where field data exist for comparison. The model can be run without larval behaviour (the simplifying assumption applied) and again with behaviour included, and these 2 predictions can be compared to the observed result. Other more direct attempts to test the simplifying assumption are few, and have had mixed results (Leis 2006).

I have developed the hypothesis of Hunt von Herbing - that behaviour should play a larger role in dispersal in warm seas than in cold ones-by presenting additional factors that support it and by extending it by implication to differences between warm seasons and cold ones. The historical factors of phylogeny and biogeography also make such regional differences likely. Testing this hypothesis requires care given the many, potentially confounding elements involved. If sustained, this hypothesis will have important implications both for dispersal in different regions and for attempts to model dispersal. At the very least, the elements presented in my development of the hypothesis provide a sound basis to treat with great caution any assumption that one size fits all with respect to dispersal of demersal fish larvae, not only with respect to regions, but also with respect to taxa.

Realistic biophysical models of dispersal are needed for a variety of important purposes, but, before realism can be achieved, we must gain an understanding of the behavioural capabilities of the larvae whose dispersal we seek to model and not just ignore these capabilities. Once the knowledge is gained, incorporation of behaviour into hydrodynamic models must take into account the issues raised above. All of these represent challenges, and many also confront the comfortable simplifying assumptions of the past, but, due to recent advances, none are completely out of reach. If realistic biophysical dispersal models of use to both researchers and managers are the goal, then we must deal with all these issues, perhaps not all at once, but certainly in the end.

Acknowledgements. I thank the organisers of the WKAMF Workshop-Alejandro Gallego, Elizabeth North and Pierre Petitgas - for inviting me to participate, and Kelly Wright for sharing some results of her $\mathrm{PhD}$ work on sensory physiology of fish larvae and for editorial assistance. This work was supported by an ARC Discovery Grant (DP0345876) and a DST International Science Linkages Grant (IAP-IST-CG03-0043) to me, and by the Australian Museum. Portions of the above text were based on a joint grant proposal with Luciano Mason, Heather Patterson and Lynne van Herwerden, and benefited from their comments. Thanks to Sue Bullock and Matt Lockett for editorial and other comments on the manuscript.

\section{LITERATURE CITED}

Atema J, Kingsford MJ, Gerlach G (2002) Larval fish could use odour for detection, retention and orientation to reefs. Mar Ecol Prog Ser 241:151-160

Bartsch J (2005) The influence of spatio-temporal egg production variability on the modelled survival of the early life history stages of mackerel (Scomer scombrus) in the eastern North Atlantic. ICES J Mar Sci 62:1049-1060

Bartsch J, Knust R (1994) Simulating the dispersion of vertically migrating sprat larvae (Sprattus sprattus (L.)) in the German Bight with a circulation and transport model system. Fish Oceanogr 3:92-105

Batty RS, Blaxter JHS, Bone Q (1991) The effect of temperature on the swimming of a teleost (Clupea harengus) and an ascidian larva (Dendrodoa grossularia). Comp Biochem Physiol A 100:297-300

Blaxter JHS (1992) The effect of temperature on larval fishes. Neth J Zool 42:336-357

Caley MJ, Carr MH, Hixon MA, Hughes TP, Jones GP, Menge BA (1996) Recruitment and the local dynamics of open marine populations. Annu Rev Ecol Syst 27:477-500

Clark DL, Leis JM, Hay AC, Trnski T (2005) Swimming ontogeny of larvae of four temperate marine fishes. Mar Ecol Prog Ser 292:287-300

Cowen RK (2002) Larval dispersal and retention and consequences for population connectivity. In: Sale PF (ed) Coral reef fishes: dynamics and diversity in a complex ecosystem. Academic Press, San Diego, CA, p 149-170

Cowen RK, Lwiza KMM, Sponaugle S, Paris CB, Olson DB (2000) Connectivity of marine populations: open or closed? Science 287:857-859

Cowen RK, Paris CB, Olson DB, Fortuna JL (2003) The role of long distance dispersal versus local retention in replenishing marine populations. Gulf Caribb Res 14:129-138

Cowen RK, Paris CB, Sirnivasan A (2006) Scaling of connectivity in marine populations. Science 311:522-527

Cushing DH (1990) Plankton production and year class strength in fish populations: an update of the match/ mismatch hypothesis. Adv Mar Biol 26:249-293

Fisher R, Leis JM, Clark DL, Wilson SK (2005) Critical swimming speeds of late-stage coral reef fish larvae: variation within species, among species and between locations. Mar Biol 147:1201-1212

Fox CJ, McCloughrie P, Young EF, Nash RDM (2006) The importance of individual behaviour for successful settlement of juvenile plaice (Pleuronectes platessa L.): a modelling and field study in the eastern Irish Sea. Fish Oceanogr 15:301-313

Frank KT, Carscadden JE, Leggett WC (1993) Causes of spatio-temporal variation in the patchiness of larval fish distributions: differential mortality or behaviour? Fish Oceanogr 2:114-123

Fuiman LA, Batty RS (1997) What a drag it is getting cold: partitioning the physical and physiological effects of temperature on fish swimming. J Exp Biol 200:1745-1755

Fuiman LA, Werner RG (2002) Fishery science: the unique contributions of early life stages. Blackwell, Oxford

Hare JA, Quinlan JA, Werner FE, Blanton BO, Govoni JJ, Forward RB, Settle LR, Hoss DE (1999) Larval transport during winter in the SABRE study area: results of a coupled vertical larval behaviour-three-dimensional circulation model. Fish Oceanogr 8(Suppl 2):57-76

Hare JA, Churchill JH, Cowen RK, Berger TJ and 5 others (2002) Routes and rates of larval fish transport from the southeast to the northeast United States continental shelf. Limnol Oceanogr 47:1774-1789 
Hart JL (1973) Pacific fishes of Canada. Bull Fish Res Board Can 180:1-740

Hellberg ME, Burton RS, Neigel JE, Palumbi SR (2002) Genetic assessment of connectivity among marine populations. Bull Mar Sci 70:273-290

Hinckley S, Hermann AJ, Mier KL, Megrey BA (2001) Importance of spawning location and timing to successful transport to nursery areas: a simulation study of Gulf of Alaska walleye pollock. ICES J Mar Sci 58:1042-1052

Houde ED (1987) Fish early life dynamics and recruitment variability. Am Fish Soc Symp 2:17-29

Houde ED (1989) Comparative growth, mortality, and energetics of marine fish larvae: temperature and implied latitudinal effects. Fish Bull (Wash DC) 87:471-495

Hunt von Herbing I (2002) Effects of temperature on larval fish swimming performance: the importance of physics to physiology. J Fish Biol 61:865-876

Iles TD, Sinclair M (1982) Atlantic herring: stock discreetness and abundance. Science 215:627-633

James MK, Armsworth PR, Mason LB, Bode L (2002) The structure of reef fish metapopulations: modelling larval dispersal and retention patterns. Proc R Soc Lond B 269: 2079-2086

Jenkins GP, King D (2006) Variation in larval growth can predict the recruitment of a temperate, seagrass-associated fish. Oecologia 147:641-649

Jones GP, Planes S, Thorrold SR (2005) Coral reef fish larvae settle close to home. Curr Biol 15:1314-1318

Kingsford MJ, Leis JM, Shanks A, Lindeman K, Morgan S, Pineda J (2002) Sensory environments, larval abilities and local self-recruitment. Bull Mar Sci 70:309-340

Leis JM (1991) The pelagic phase of coral reef fishes: larval biology of coral reef fishes. In: Sale PF (ed) The ecology of fishes on coral reefs. Academic Press, San Diego, CA, p $183-230$

Leis JM (2006) Are larvae of demersal fishes plankton or nekton? Adv Mar Biol 51:59-141

Leis JM, Carson-Ewart BM (2003) Orientation of pelagic larvae of coral-reef fishes in the ocean. Mar Ecol Prog Ser 252:239-253

Leis JM, Carson-Ewart BM (2004) The larvae of Indo-Pacific coastal fishes: a guide to identification. Brill, Leiden

Leis JM, McCormick MI (2002) The biology, behaviour and ecology of the pelagic, larval stage of coral-reef fishes. In: Sale PF (ed) Coral reef fishes: new insights into their ecology. Academic Press, San Diego, CA, p 171-199

Leis JM, Hay AC, Trnski T (2006) In situ behavioural ontogeny in larvae of three temperate, marine fishes. Mar Biol 148:655-669

Montgomery JC, Tolimieri N, Haine OS (2001) Active habitat selection by pre-settlement reef fishes. Fish Fish 2: 261-277

Montgomery JC, Jeffs A, Simpson SD, Meekan M, Tindle C (2006) Sound as an orientation cue for the pelagic larvae of reef fishes and decapod crustaceans. Adv Mar Biol 51: 143-196

Morgan SG (2001) The larval ecology of marine communities.

Editorial responsibility: Alejandro Gallego (Contributing

Editor), Aberdeen, UK
In: Bertness MD, Gaines SD, Hay ME (eds) Marine community ecology. Sinauer Press, Sunderland, MA, p 159-181

Moser HG (1996) The early stages of fishes in the California Current region. Calif Coop Ocean Fish Invest Atlas 33: $1-1505$

Moser HG, Richards WJ, Cohen DM, Fahay MP, Kendall AW, Richardson SL (1984) Ontogeny and systematics of fishes. Special Publication No. 1, American Society of Ichthyologists and Herpetologists, Lawrence, KS

Myrberg AA, Fuiman LA (2002) The sensory world of coral reef fishes. In: Sale PF (ed) Coral reef fishes: dynamics and diversity in a complex ecosystem. Academic Press, San Diego, CA, p 123-148

Nilsson GE, Östlund-Nilsson S, Penfold R, Grutter AS (2007) From record performance to hypoxia tolerance-respiratory transition in damselfish larvae settling on a coral reef. Proc R Soc Lond B 274:79-84

Palumbi SR (2001) The ecology of marine protected areas. In: Bertness MD, Gaines SD, Hay ME (eds) Marine community ecology. Sinauer Press, Sunderland, MD, p 509-530

Palumbi SR (2003) Population genetics, demographic connectivity, and the design of marine reserves. Ecol Appl 13: $146-158$

Pearre S (1979) Problems of detection and interpretation of vertical migration. J Plankton Res 1:29-44

Roberts CM (1997) Connectivity and management of Caribbean coral reefs. Science 278:1454-1456

Robertson DR, Allen GR (2002) Shorefishes of the tropical eastern Pacific: an information system (CD-ROM, Version 1.0). Smithsonian Tropical Research Institute, Balboa

Sale PF (1991) Reef fish communities: open nonequilibrial systems. In: Sale PF (ed) The ecology of fishes on coral reefs. Academic Press, San Diego, CA, p 564-598

Sale PF (2004) Connectivity, recruitment variation, and the structure of reef fish communities. Integr Comp Biol 44: 390-399

Sinclair M (1988) Marine populations: an essay on population regulation and speciation. University of Washington Press, Seattle, WA

Sponaugle S, Cowen RK, Shanks A, Morgan SG and 7 others (2002) Predicting self-recruitment in marine populations: biophysical correlates. Bull Mar Sci 70:341-376

Swearer SE, Shima JS, Hellberg ME, Thorrold SR and 6 others (2002) Evidence of self-recruitment in demersal marine populations. Bull Mar Sci 70:251-272

Thorrold SR, Jones GP, Hellberg ME, Burton RS, Swearer SE, Neigel JE, Morgan SG, Warner RR (2002) Quantifying larval retention and connectivity in marine populations with artificial and natural markers. Bull Mar Sci 70:291-308

Trnski T (2002) Behaviour of settlement-stage larvae of fishes with an estuarine juvenile phase: in situ observations in a warm-temperate estuary. Mar Ecol Prog Ser 242:205-214

Wright KJ, Higgs DM, Belanger AJ, Leis JM (2005) Auditory and olfactory abilities of pre-settlement larvae and postsettlement juveniles of a coral reef damselfish (Pisces: Pomacentridae). Mar Biol 147:1425-1434

Submitted: June 7, 2006; Accepted: April 30, 2007

Proofs received from author(s): August 28, 2007 